\title{
Spatial-temporal distribution and impact factors of irrigation water use efficiency in the grain production of China
}

\author{
Xiangping Guo ${ }^{1,2}$, Mengyang $\mathrm{Wu}^{1,2}$, Xinchun $\mathrm{Cao}^{1,2^{*}}$, Zhenchang Wang ${ }^{1,2}$ \\ (1. Key Laboratory of Efficient Irrigation-Drainage and Agricultural Soil-Water Environment in Southern China of \\ Ministry of Education, Hohai University, Nanjing 210098, China; \\ 2. College of Agricultural Engineering, Hohai University, Nanjing 210098, China)
}

\begin{abstract}
The marginal water productivity (MWP) model for the real irrigation water use performance and productivity assessment, applies to the regional scale was established in this study. The temporal-spatial patterns and attribution analyses of the indicator were conducted using spatial autocorrelation and path analysis methods. The results showed that with an average annual increase of $3.4 \%$, the national MWP was estimated to be $0.542 \mathrm{~kg} / \mathrm{m}$, between 1998 and 2010 . The spatial autocorrelation analysis results showed the global Moran's I inspection values $(Z)$ were higher than the confidence level, and the provinces, municipalities and autonomous regions (PAMs) with similar MWP values showed significant aggregation. Regions with a high value are centered in the middle and lower streams of the Yellow River, and those regions with a lower MWP were distributed in northeastern China and south of the Yangtze River. The precipitation and temperature are the major meteorological factors that determined the indicator, while extending the fertilizer and agricultural machinery input is the effective approach for improving the regional MWP. The major grain producing areas of North and Northeast China should take measures to raise their MWP, ensure food security and the sustainable use of water resources.
\end{abstract}

Keywords: water use efficiency, the marginal output, spatial autocorrelation, path analysis, food security DOI: $10.25165 /$ j.ijabe.20181105.3588

Citation: Guo X P, Wu M Y, Cao X C, Wang Z C. Spatial-temporal distribution and impact factors of irrigation water use efficiency in the grain production of China. Int J Agric \& Biol Eng, 2018; 11(5): 131-138.

\section{Introduction}

With an annual grain production of more than $500 \mathrm{M}$ ton in recent years ${ }^{[1]}$, the populous country of China has successfully ensured the per capita food production. Farmland irrigation used approximately $300 \mathrm{G} \mathrm{m}^{3}$ of the blue water resources (accounting for $90 \%$ of the total agricultural water use) and produced $75 \%$ of the national grain outputs ${ }^{[2,3]}$, played an irreplaceable role in grain production and water utilization of China. Meanwhile, the country faced a shortage of water supply and degeneration of the ecology due to the unrestrained use of water resources in agricultural production ${ }^{[4-7]}$. Since agriculture plays the largest part in the water use ${ }^{[3,8]}$, the promotion of water use efficiency in agriculture production is critical for alleviating the crucial shortage of water resources. The theories and methodologies of the agriculture water utilization evaluation have been a hot topic for research in water resources and environmental management ${ }^{[9-12]}$.

The two categories of parameters-irrigation efficiency and water productivity-are most commonly used in the water utilization evaluation in the process of agricultural production ${ }^{[13]}$. Irrigation efficiency is a complex and useful measure of the irrigation

Received date: $2017-06-23$ Accepted date: 2018-04-03

Biographies: Xiangping Guo, Profession, research interests: agricultural water management, Email: xoguo@hhu.edu.cn; Mengyang Wu, PhD candidate, research interests: agricultural water management, Email: wumengyang@hhu.edu.cn; Zhenchang Wang, Profession, research interests: agricultural water management, Email: wangzhenchang@hhu.edu.cn.

*Corresponding author: Xinchun Cao, Profession, research interests: agricultural water management. College of Agricultural Engineering, Hohai University, Nanjing, Jiangsu 210098, China. Tel: +86-18761866817, Email: caoxinchun@hhu.edu.cn. performance and can be expressed by various indicators, such as irrigation efficiency and net or effective irrigation efficiency ${ }^{[14]}$. The classical irrigation efficiency refers to the ratio between the irrigation water consumed by the crops of an irrigation farm or project and the water diverted from a river or other natural water source into the farm project's canal or canals ${ }^{[15,16]}$. This concepts ignored the irrigation water return flow that re-enters the water supply, and the effective irrigation efficiency was defined as the crop consumptive use of the applied irrigation water divided by the effective use ${ }^{[16,17]}$. Such terminologies as irrigation water withdrawal, water application efficiency, evapotranspiration, water consumption, return flow, and net depletion ${ }^{[14,16]}$ are closely related to the irrigation efficiency assessment. The water productivity indicators are used to account for the products generated per unit of water consumed or used in many scientific disciplines ${ }^{[18]}$. The agriculture water productivity, which was originally defined by Molden ${ }^{[19]}$, is used to measure the relationship between the crop yield and the amount of water involved in the process of crop production and is expressed as the crop production per unit volume of water resources ${ }^{[20,21]}$. The numerator was expressed in terms of the crop yield $\left(\mathrm{kg} / \mathrm{hm}^{2}\right)$, and several options are available to define the volume of water per unit of area $\left(\mathrm{m}^{3} / \mathrm{hm}^{2}\right)$ in the denominator. For various water input options, the agriculture water productivity can be defined or named as the crop water use efficiency (WUE), gross inflow water productivity, generalized water productivity, evapotranspiration water productivity and irrigation water productivity ${ }^{[22,23]}$. Promoting water productivity is a direct and efficient way to achieve efficient water use and has been extensively studied in water resources management ${ }^{[10,24-27]}$. Associated discussions have pointed out the primary ways by which water productivity can be increased, such as increasing the 
productivity per unit of evapotranspiration, minimizing the non-beneficial depletion by reducing pollution and flows to sinks, reusing the return and drainage flows, and reallocating water from the lower value to higher value uses within the basin ${ }^{[27]}$. The irrigation water is the most important water resource and is also a part of the water input of the water productivity; hence, the water productivity and irrigation efficiency indicators were usually combined in the water utilization evaluation, especially in the irrigation system. The effects of irrigation on the crop yield, water use and water productivity in the macro scale area were gradually became a concern for scholars. An investigation conducted by $\mathrm{Gao}^{[28]}$ concluded that the grain yield in the cropland equipped with irrigation was approximately one to two times of that fed only by precipitation. Liu et al. ${ }^{[29]}$ simulated the role of irrigation in the winter wheat yield and crop water productivity in China by using a GIS-based crop model. Based on a crop-model-coupled-statistics approach, Cao et al. ${ }^{[3,30]}$ evaluated the water utilization and production of the main grain crop for the irrigated and rain-fed farmlands in China.

Irrigation increased the crop yield and the field water use efficiency, especially in the arid areas. However, this finding also means that more blue water resources are needed for crop production. The reduction of irrigation water in agriculture production is feasible and meaningful for water resources management. An appropriate indicator is needed to account for the water utilization and crop production. By extending the notion of crop water productivity, and based on the crop-water relationship in the irrigated and rain-fed croplands assessed at multiple scales, a category of indicators for the role of irrigation accounting was established in this study. The purpose of this study is to calculate the MWP in grain production and to quantify their temporal-spatial distribution and effect factors in China. In addition, based on the MWP performance and its effect factors, strategies for the regional water resources management and food security were also discussed.

\section{Materials and methods}

\subsection{Marginal water productivity (MWP)}

The marginal benefit refers to the annual percentage return on the last additional unit of resources input, and can be calculated as follows $^{[31]}$ :

$$
M P=\frac{\Delta \text { Output }}{\Delta \text { input }}
$$

As we all know, the water resources investment and crop yield were higher in the irrigated cropland compared to the rain-fed cropland. The marginal benefit of irrigation (marginal water productivity, MWP) can be defined as follows:

$$
M W P=\frac{\left(Y_{I}-Y_{R}\right)}{I W U}
$$

where, $Y_{I}$ and $Y_{R}$ are the crop yield of irrigated and rain-fed cropland, respectively, in the unit of $\mathrm{kg} / \mathrm{hm}^{2} ; I W U$ is the irrigation water use for the per unit irrigation area in the unit of $m 3 / \mathrm{ha}$. The provincial irrigated crop yield $\left(Y_{I}\right)$ is estimated via a weighted mean:

$$
Y_{I}=\frac{\sum Y_{I D}^{i} \times A^{i}}{\sum A^{i}}
$$

where, $Y_{I D}^{i}$ is the crop yield in the $i^{\text {th }}$ irrigation district, $\mathrm{kg} / \mathrm{hm}^{2}$; and $A^{i}$ is the irrigation area of the $i^{\text {th }}$ irrigation district, $\mathrm{hm}^{2}$. The rain-fed crop yield can be calculated by

$$
\begin{gathered}
Y_{R}=\frac{G O_{T}-Y_{I} \times A_{I}}{A_{R}} \\
A_{R}=A-A_{I}
\end{gathered}
$$

where, $G O_{T}$ is the provincial total output of the grain products, $\mathrm{t} ; A_{I}$ and $A_{R}$ are the areas of the irrigated and rain-fed farmland, $\mathrm{hm}^{2}$.

Similar to the water productivity (WP), the unit of the marginal water productivity (MWP) is $\mathrm{kg} / \mathrm{m}^{3}$. MWP belongs to the category of water productivity indexes and quantifies the additional grain production per unit blue-water input. The water productivity (WP) can be defined as the ratio between the crop yield achieved and the irrigation water withdrawal, the total water use or the consumptives water use, when evaluating the performance of the irrigation systems $\mathrm{s}^{[22,23]}$. Conversely, the marginal water productivity (MWP) cannot be replaced by any other form of a water productivity index. The MWP reveals the role of irrigation in crop production and water utilization. Improving the MWP is the fundamental measure for reducing the agricultural blue water resource usage to maintain regional water and ecological security.

\subsection{Spatial autocorrelation analysis}

The spatial autocorrelation analysis method correlates the variables with spatial locations and reflects the degree of spatial dependence between the values of the variables geographically ${ }^{[32-34]}$. Moran's I, Geary's C, and Getis are the most commonly used methods in the spatial autocorrelation analysis ${ }^{[35]}$, and Moran's I is the most often used method of these three. Moran's I is a weighted correlation coefficient that detects departures from the spatial randomness and determines whether the neighboring areas are more similar than expected under the null hypothesis ${ }^{[36]}$. The global Moran's I ${ }^{[37,38]}$ was used to detect the global spatial autocorrelation of the MWP in this study and to disclose the spatial pattern of the MWPs with the Z score at the province level. A statistically significant estimate of Moran's I indicates that the neighboring counties have a similar prevalence rate of the MWP, and the cases are likely to cluster at the PAMs level. The local Moran' $\mathrm{I}^{[38]}$ is used to measure the overall clustering $\mathrm{t}$ reveal the location of the clusters. The bivariate spatial autocorrelation scatterplot is a graphic tool for detecting the local spatial association. It provides a way to categorize the nature of the spatial autocorrelation into four types: high-high $(\mathrm{HH})$, low-low (LL), high-low (HL) and low-high (LH). The first two indicate the potential spatial clusters of similar MWP, i.e., positive autocorrelation with high or low similar values. The latter two express the potential spatial clusters of dissimilar values. The significance of the global and local Moran statistics was evaluated with Monte Carlo randomizations based on a non-parametric conditional randomization approach, where the value $\mathrm{x}$ at site $\mathrm{i}$ is held fixed and the remaining values are randomly permutated over the other locations in the global dataset ${ }^{[39]}$. Since the local Moran statistics calculated for each PAMs are not independent due to the overlapping neighborhoods, the $\mathrm{p}$ values were corrected with a 0.01 level of significance. The software $\mathrm{GeoDa}^{\mathrm{TM}} 0.9 .5-\mathrm{i}^{[39]}$ was used to conduct the spatial autocorrelation analysis of the MWP in this study.

\subsection{Path analysis (PA)}

In this study, the path analysis (PA) method was used to determine the effect of the various factors on the MWP. The PA is based on multiple regressions, and then decomposes the 
correlation coefficient. The direct effects, indirect effects and comprehensive effects of a certain variable on the dependent variable (MWP) are expressed by the direct path, indirect path and total path coefficient, respectively ${ }^{[40]}$. PA provides an effective way to find the direct and indirect effects between the independent variable and the dependent variable. The primary process of the PA is as follows: for the general multiple linear regression analysis, the independent variables is $x_{1}, x_{2}, \ldots, x_{k}$, the dependent variable is $y$, and the relationship between $\mathrm{x}$ and $\mathrm{y}$ can be expressed by the following the regression equation ${ }^{[41]}$ :

$$
y=\beta_{0}+\beta_{1} \cdot x_{1}+\beta_{2} \cdot x_{2}+\ldots . .+\beta_{K} \cdot x_{K}
$$

Using the least squares method to solve the regression coefficient and the number of changes, a simple correlation coefficient decomposition can be evaluated by following equations:

$$
\left\{\begin{array}{l}
P_{1 y}+r_{12} \cdot P_{2 y}+r_{13} \cdot P_{3 y}+\ldots+r_{1 k} \cdot P_{K y}=r_{1 y} \\
r_{21} \cdot P_{1 y}+P_{2 y}+r_{23} \cdot P_{3 y}+\ldots+r_{2 k} \cdot P_{K y}=r_{2 y} \\
\quad \ldots \\
r_{K 1} \cdot P_{1 y}+r_{K 2} \cdot P_{2 y}+r_{K 3} \cdot P_{3 y}+\ldots+P_{K y}=r_{K y}
\end{array}\right.
$$

where, $r_{i j}$ is the simple correlation coefficient between xi and $x_{j} ; r_{i y}$ is the simple correlation coefficient between $x_{i}$ and y; $P_{I y}$ is the direct path coefficient which represents the direct effect of $x_{i}$ on $y$, and $r_{i j} P_{j y}$ is the indirect path coefficient, showing the indirect effect of $x_{i}$ on the dependent variable y by $x_{j}$. Eight factors relative humidity (RH), average temperature (AT), precipitation (P), sunshine duration (SSD), fertilizer rate per sown area (FR), dosage of pesticide per sown area (DP), agricultural machinery power per sown area (AM), irrigation proportion of arable land (IP) and irrigation efficiency (IE) were selected for the path analysis in this study.

\subsection{Data sources}

Following the definitions used in the Chinese National Statistics, grain crops include cereals (i.e., rice, wheat, maize), legumes (soybean and other leguminous crops), and tubers (potato, sweet potato and other types of tubers). The irrigation water capacity (IWC, the irrigation water), crop yield (Y), irrigation efficiency (IE) and irrigated area of 459 irrigation districts in 31 province autonomous regions and municipalities (PAMs) of China (Figure 1) were collected from the National Center of Irrigation and Drainage Development, Ministry of Water Resources. The meteorological parameters, including relative humidity $(\mathrm{RH})$,

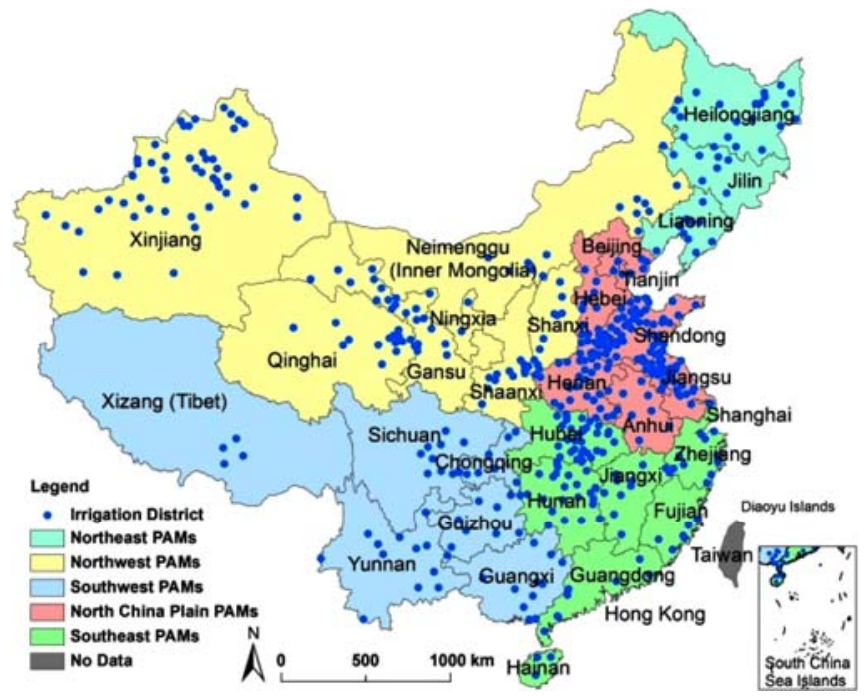

Figure 1 Distribution of the 459 irrigation districts and regional delimitation average temperature (AT), precipitation $(\mathrm{P})$ and sunshine duration (SD), were downloaded from the Climatic Data Center of China's Meteorological Administration (http://data.cma.cn). The provincial total output of grain products $\left(\mathrm{GO}_{\mathrm{T}}\right)$, irrigated rain-fed farmland (sown area, AI and AR) and population were collected from the China Statistical Yearbooks in 1999-2011. The water resources and agricultural water withdrawals of China were referenced from the China Water Resources Bulletins in 1998-2010.

\section{Results}

\subsection{MWP}

The national MWP was calculated to be approximately $0.542 \mathrm{~kg} / \mathrm{m}^{3}$ in the period between 1998 and 2010, indicating that no more than $0.600 \mathrm{~kg}$ of grain product could be gained when $1 \mathrm{~m}^{3}$ water resources were diverted to the irrigation farmland of China. Considering the representativeness, provincial values of the MWP in the starting year (1998), middle year (2005) and last year (2010) of the observing period 1998-2010 are shown in Figure 2. To determine the change rate of the MWP over time, Figure 2 also shows the average annual change rate of the MWP for each of the PAMs. In addition, the primary statistics for the MWP in the different years were calculated and listed in Table 1 for the interregional differences that the MWP revealed.

It is illustrated in Figure 2 that from 1998 to 2010, the MWP in almost all the PAMs showed a tendency to increase over time, and the national value increased from $0.414 \mathrm{~kg} / \mathrm{m}^{3}$ to $0.665 \mathrm{~kg} / \mathrm{m}^{3}$ (Table 1) with an average annual change rate of approximately $3.4 \%$. The national irrigation efficiency and farmland irrigation rate increased from 0.420 and $41 \%$ in 1998 to 0.492 and $50 \%$ in 2010 , and the irrigation water consumption was reduced from approximately $8900 \mathrm{~m}^{3} / \mathrm{hm}^{2}$ to $7300 \mathrm{~m}^{3} / \mathrm{hm}^{2}$, which is the reason that the MWP increased over time. In addition, the primary statistics for the MWP in different years were calculated for the water resources input due to the increase of irrigation efficiency. The change of the MWP has not remained consistent among the PAMs. With an average annual growth rate of $7 \%$ and $6.5 \%$, respectively, Inner Mongolia and Sichuan were the fastest growing PAMs in China. The average annual growth rate of these two is significantly higher than that of the other PAMs. The yearly growth of the MWP in Gansu, Xizang, Liaoning, Anhui, Guizhou and Jiangsu is rapid as well, and each of them held an average annual change rate of approximately 5.3\%. More than half of the PAM (16) has an average annual increase of approximately $2.5 \%$ to $4.5 \%$, while Jiangxi and Hainan have the lowest rates of change, only $1.7 \%$ and $1.5 \%$, respectively.

Table 1 National value and main statistics for the MWP at the regional and field scales

\begin{tabular}{ccccccc}
\hline Year & $\begin{array}{c}\text { National } \\
\text { value } \\
/ \mathrm{kg} \cdot \mathrm{m}^{-3}\end{array}$ & $\begin{array}{c}\text { Max } \\
/ \mathrm{kg} \cdot \mathrm{m}^{-3}\end{array}$ & $\begin{array}{c}\text { Min } \\
/ \mathrm{kg} \cdot \mathrm{m}^{-3}\end{array}$ & $\begin{array}{c}\text { Mean } \\
/ \mathrm{kg} \cdot \mathrm{m}^{-3}\end{array}$ & $\begin{array}{c}\text { Standard } \\
\text { deviation (SD) } \\
/ \mathrm{kg} \cdot \mathrm{m}^{-3}\end{array}$ & $\begin{array}{c}\text { Coefficient of } \\
\text { Variation } \\
(\mathrm{CV})\end{array}$ \\
\hline 1998 & 0.414 & 0.982 & 0.194 & 0.447 & 0.229 & 0.512 \\
2005 & 0.548 & 1.253 & 0.247 & 0.535 & 0.280 & 0.523 \\
2010 & 0.665 & 1.436 & 0.262 & 0.661 & 0.340 & 0.514 \\
$98-10$ & 0.542 & 1.224 & 0.242 & 0.548 & 0.279 & 0.510 \\
\hline
\end{tabular}

As shown in Figure 2 and Table 1, the changing extent of the MWP in each of the PAMs is small, and the size relationship of the MWP among the PAMs is similar in different years. At the same time, the primary statistics, such as the maximum, minimum and average, increased over time consistently with the national values. The coefficient of variation (CV) of the MWP for 31 PAMs 
remained constant at approximately 0.515 in each of the selected years. Thus, the average values of the three representative years for each of the PAMs were calculated and used as the multi-year average values for the MWP comparison at the provincial level. The results show that the MWP in Shaanxi reached $1.224 \mathrm{~kg} / \mathrm{m}^{3}$, ranking the highest of all regions in the country. The MWPs in Shandong, Hebei and Henan were above $1.000 \mathrm{~kg} / \mathrm{m}^{3}$ as well, and these are the PAMs with a high marginal efficiency of irrigation water resources. In addition, the MWP in the other 8 PAMs was estimated to exceed the national value $\left(0.542 \mathrm{~kg} / \mathrm{m}^{3}\right)$, including Shanxi, Beijing, Tibet, Hubei, Sichuan, Gansu, Anhui and Ningxia. In contrast, the MWP was no more than $3.000 \mathrm{~kg} / \mathrm{m}^{3}$ in the seven PAMs of Guizhou, Jilin, Guangxi, Hainan, Guangdong, Fujian and Shanghai. Almost all of the PAMs with a low MWP are located in southern China. Although the MWP in the northwestern PAMs was lower than the national value due to the natural drought condition, it still reached approximately $0.500 \mathrm{~kg} / \mathrm{m}^{3}$ and was higher than the southern PAMs.

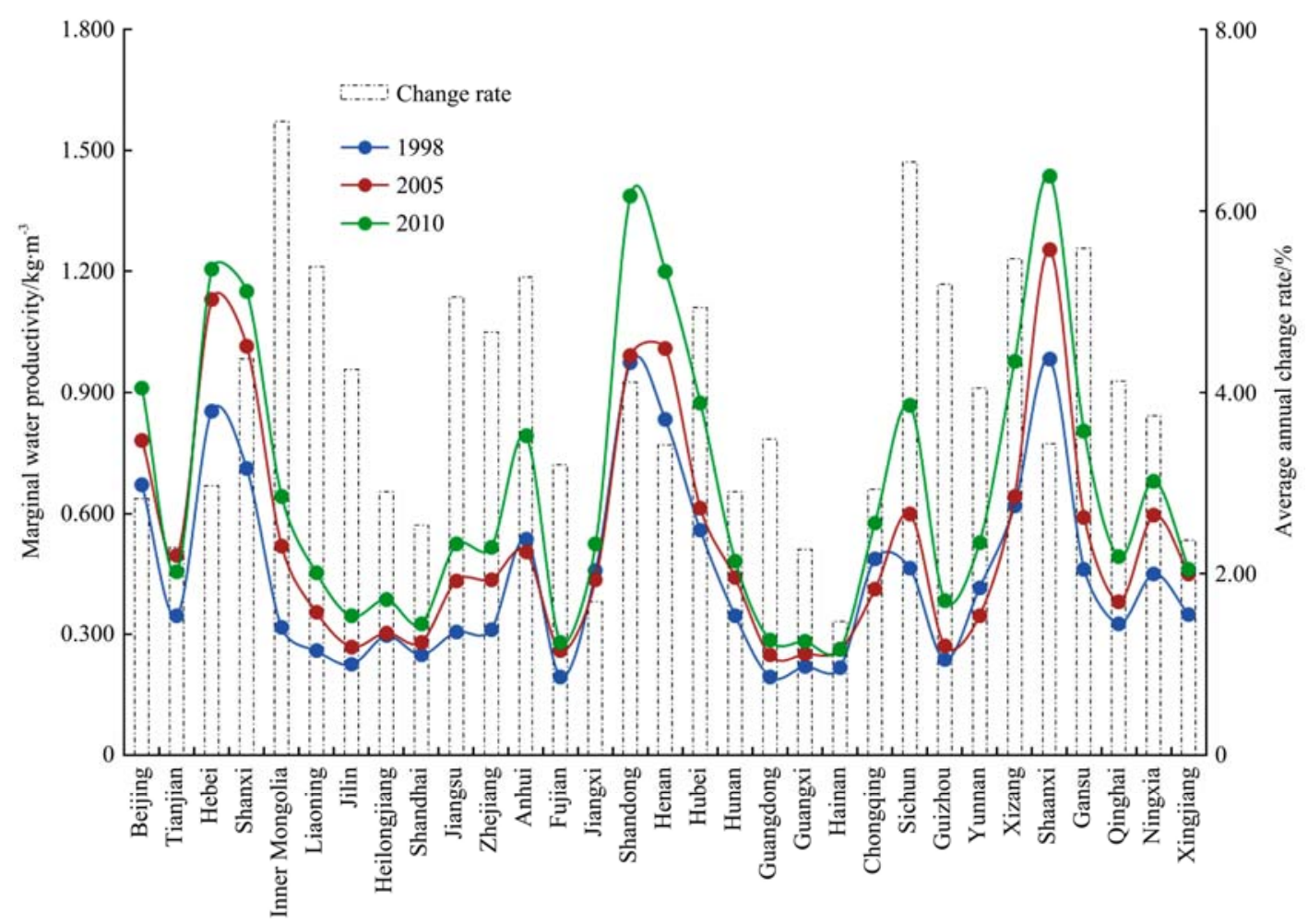

Figure 2 Actual water productivity of the irrigation (MWP) and its change rate for 31 PAMs of China. (Change rate $\left.=\frac{1}{2} \sum_{n=1998}^{2009}\left(\frac{M W P_{n+1}-M W P_{n}}{M W P_{n}}\right)\right)$

\subsection{Spatial-temporal pattern of the MWP}

The spatial autocorrelation method is used to explore the spatial distribution pattern of the MWP and its change with time at the provincial level in China, and the global Moran's I value and its test of the MWP in the selected years are calculated and listed in Table 2. Almost all of the global Moran's I values were significantly greater than 0 and above 0.4000 , and none of the $Z$ scores were below $2.58(p=0.01)$. The average global Moran's I and Z score values of the MWP during 1998-2010 reaches as high as 0.4344 and 4.1398 , respectively. It is concluded that a $99 \%$ confidence interval of the Moran's I value is positive, which demonstrates that a high global spatial autocorrelation of the MWP is detected at the provincial level of China during the study years. The spatial association clustering and distribution features analysis, based on the local Moran's I, were also conducted. The difference of both the value of the global autocorrelation Moran's I and the Z score of the MWP among the three studied years is tiny (see Table 2). To further analyze the local spatial distribution pattern of the MWP, the local Moran's I value of the PAMs are calculated, and the local autocorrelation attribute can be judged. Finally, a LISA (Local indicators of spatial association) cluster map is formed, as shown in Figure 3.
Table 2 Moran's I test for the marginal water productivity (MWP) of 1998, 2005, 2010 and the period 1998-2010

\begin{tabular}{ccccc}
\hline Indicator & 1998 & 2005 & 2010 & $98-10$ \\
\hline Moran's I & 0.3988 & 0.4664 & 0.4136 & 0.4344 \\
Z Score & 3.8313 & 4.4547 & 3.9117 & 4.1398 \\
P-value & 0.0007 & 0.0002 & 0.0007 & 0.0003 \\
\hline
\end{tabular}

Figure 3 illustrates that the color of 28 regions in the observed years are identical. In the other words, the local spatial autocorrelation pattern of the MWP is similar in different phases. The PAMs with different colors among the MWP are in the humid areas of the Yangtze River (such as Jiangxi, Anhui and Chongqing). The amount of precipitation may be the main reason for the spatial pattern difference of the irrigation water productivity. Most PAMs show the High-High (HH) and Low-Low (LH) autocorrelation type. HH PAMs are distributed in north of the Yangze River and the plain of the middle and lower reaches of the Yellow River. LL ones are distributed in the southern Yangze River and the northeast of China. Most of the PAMs (such as Xinjiang, Qinghai and Inner Mongolia) located in the northwest belong to the LH type. The 10 regions belonging to the HH type include Sichuan, Beijing, Hebei, Shaanxi, Ningxia, Henan, Shandong, Hubei, Gansu and Shanxi, and 9 regions belonging to 
the LL type include Jilin, Heilongjiang, Yunnan, Guizhou, Hunan, Guangxi, Guangdong, Fujian and Zhejiang, account for $32.2 \%$ and $29.0 \%$ of PAMs, respectively. The other regions with an MWP belonging to the Low-High (LH) type are Tianjin, Liaoning and Hainan. Only Xizang (Tibet) belongs to the High-Low (HL) type in all of the WP indexes ${ }^{[23]}$. MWP in Liaoning and its neighbors, Heilongjiang, Jilin, Hebei and Inner Mongolia, were 0.687, 0.536 2.080 and $1.402 \mathrm{~kg} / \mathrm{m}^{3}$ in $1998-2010$, respectively. Liaoning's local spatial pattern is classified into low-high clusters due to the significant influence from Hebei and Inner Mongolia.

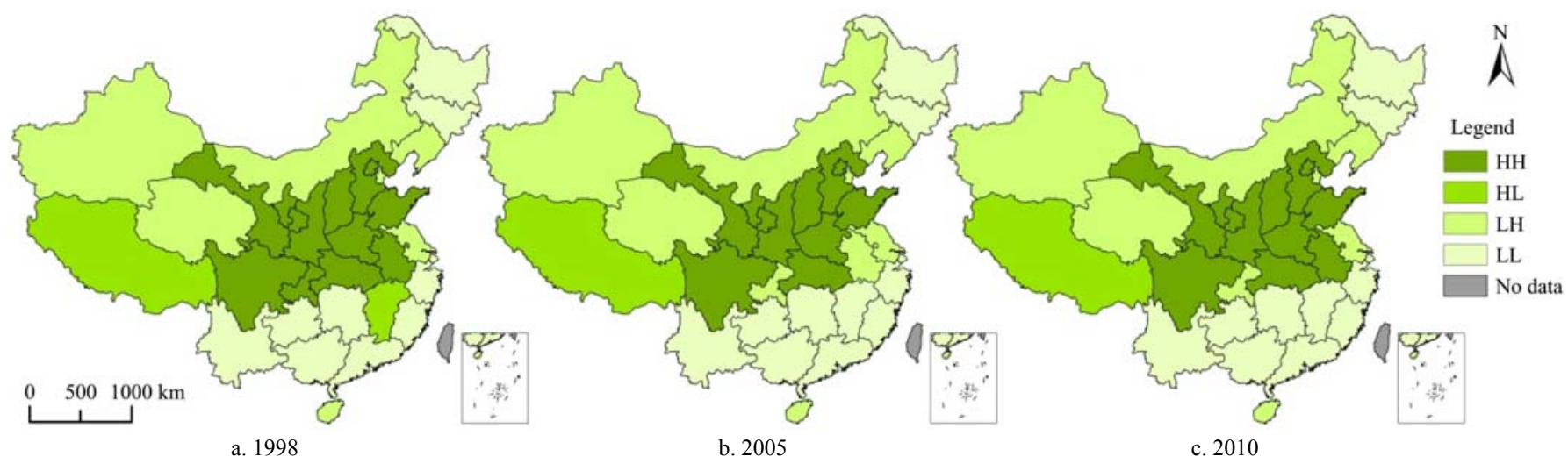

a. 1998

b. 2005

c. 2010

Figure 3 LISA cluster map of the marginal water productivity for 31 PAMs in 1998, 2005 and 2010

The spatial autocorrelation analysis results show that the MWP at the provincial level in China are significantly clustered, both globally and locally. The provinces with similar irrigation water productivity values show significant similarity on MWP. The provinces with high WPs are centered in the Huang-Huai-Hai Plain, while the provinces with low WPs are distributed in the south and the northeast of China. The southwest-to-southeastern coastal area is a region with abundant rainfall and a significant yield of grain crops can be reached under no irrigation condition. The effect of irrigation on crop production is not as good as that of Huang-Huai-Hai Plain and the surrounding provinces. Although Jilin and Heilongjiang's crop output per unit area is high in northeast, the MWP local spatial autocorrelation attribute has been LL due to the extensive management and extensive waste of irrigation water resources while planting a large amount of high water consumption rice. Due to the natural and agricultural production as well as the economic and social conditions, the provinces of Inner Mongolia, Liaoning, and Jiangsu are in the $\mathrm{HH}$ and LL areas. The MWP in Xinjiang, Qinghai and Tianjin is in the middle level but is significantly less than the neighboring provinces with similar conditions. Therefore, the LISA attribute presents as LH. Chongqing and Anhui swing in the HH and LL, which is related to the rapid economic development and agricultural production levels in the middle and lower reaches of the Yangtze River, resulting in the local feature of the MWP being changed between HH and LL's intensity of radiation. Jiangxi changed from the HL area in 1998 into the later LL area, which was affected by a slower MWP growth rate of that province and the smaller gap between the southYangtze River provinces.

\subsection{Impact factors of MWP}

The results of the path analysis are shown in Table 3 . Table 3 shows the positive total impact of meteorological and agricultural production inputs on the MWP, except for the average temperature (AT). The remaining factors are positively correlated with the MWP, and the correlation between the precipitation (P) and irrigation proportion of arable land (IP) is strong while the correlation between the relative humidity $(\mathrm{RH})$ and the average temperature (AT) is weak. However, it is necessary to define the actual impact degree and the influencing method of each factor to improve the MWP, while the direct and indirect observation of the coefficient should be integrated. On the aspect of the direct effect, the average temperature (AT), the agricultural machinery power per sown area (AM) and the fertilizer rate per sown area (FR)'s positive direct impact is greater, while the precipitation $(\mathrm{P})$ and the amount of sunshine duration (SSD)'s negative direct impact are larger. The dosage of pesticide per sown area (DP), relative humidity (RH), irrigation proportion of arable land (IP) and irrigation efficiency (IE) did not significantly affect the MWP in space. The difference of the specific indicator between the direct path coefficient and the total coefficient of influence is explained by the indirect influence. For instance, the farmland irrigation rate has the greatest effect on the MWP, but it cannot explain how the MWP increases the irrigation proportion of arable land (IP) directly because it mainly affects the MWP indirectly through the agricultural machinery, the average temperature (AT), and the fertilizer rate per sown area (FR). The relative humidity (RH) and dosage of pesticide per sown area (DP) also impacted the MWP indirectly through the precipitation $(\mathrm{P})$ and agricultural machinery power per sown area (AM), respectively. As the most commonly used indicator of the efficiency of the irrigation water resources utilization, the direct path coefficient of the irrigation efficiency is low, and it did not obviously impact the MWP.

The average temperature affects the crop growth process and the agricultural production pattern. Higher temperature is beneficial to the formation of the crop growth and yield, also enlarge the region's multiple cropping indexes. This significantly increases the grain output per unit area, and significantly increases the MWP in the case of different crop irrigation needs. The input of fertilizer and agricultural machinery power is the primary factor to improve the agricultural production efficiency and output capacity, and the two inputs can play active roles in improving the crop yield and water use efficiency. Therefore, this approach can promote the improvement of the MWP. Precipitation is an important source of water during the crop growth (green water), and abundant rainfall can guarantee the level of grain yield per hectare without irrigation at a large extent, thus limit the effect of irrigation on the crop yield promotion. Therefore, precipitation can directly reduce the area's MWP. The regional irrigation rates and irrigation efficiency reflect the irrigation development. However, these two factors also reflect the irrigated area and the engineering level in the construction. The development of the irrigation scale can enhance the regional food security capacity, but 
it will not affect the real productivity of the irrigation water resources. In addition, the irrigation efficiency of different regions has minor difference, average efficiency values locate in the range of $0.45-0.60$, which is an important factor in contributing to the smaller influence coefficient between the irrigation efficiency and the MWP. The results of the path analysis described the relationship between different factors and MWP, also revealed the way to enhance the regional MWP.

Table 3 Path analysis result of the impact of the influencing factors on the marginal water productivity

\begin{tabular}{|c|c|c|c|c|c|c|c|c|c|c|c|}
\hline \multirow{2}{*}{ Factors } & \multirow{2}{*}{$\begin{array}{l}\text { Direct path } \\
\text { coefficient }\end{array}$} & \multicolumn{9}{|c|}{ Indirect path coefficient } & \multirow{2}{*}{$\begin{array}{c}\text { Total } \\
\text { influence }\end{array}$} \\
\hline & & RH & AT & $\mathrm{P}$ & SSD & FR & DP & $\mathrm{AM}$ & IP & IE & \\
\hline RH & 0.008 & & 0.209 & -0.314 & 0.196 & 0.067 & -0.051 & -0.076 & -0.004 & -0.008 & 0.020 \\
\hline $\mathrm{AT}$ & 0.325 & 0.005 & & -0.268 & 0.123 & 0.141 & -0.068 & -0.025 & 0.015 & -0.021 & -0.097 \\
\hline $\mathrm{P}$ & -0.404 & 0.006 & 0.215 & & 0.149 & 0.064 & -0.057 & -0.087 & 0.001 & -0.019 & 0.273 \\
\hline SSD & -0.239 & -0.007 & -0.167 & 0.253 & & -0.038 & 0.028 & 0.075 & 0.004 & 0.008 & 0.156 \\
\hline DP & -0.108 & 0.004 & 0.205 & -0.213 & 0.062 & 0.132 & & 0.038 & 0.021 & 0.001 & 0.250 \\
\hline $\mathrm{AM}$ & 0.292 & -0.002 & -0.027 & 0.120 & -0.061 & 0.063 & -0.014 & & 0.019 & 0.028 & 0.125 \\
\hline IP & 0.043 & -0.001 & 0.114 & -0.010 & -0.024 & 0.113 & -0.053 & 0.130 & & 0.011 & 0.281 \\
\hline IE & 0.074 & -0.001 & -0.092 & 0.103 & -0.024 & 0.035 & -0.002 & 0.109 & 0.007 & & 0.135 \\
\hline
\end{tabular}

Note: Factors in Table 3 are relative humidity (RH), average temperature (AT), precipitation (P), sunshine duration (SSD), fertilizer rate per sown area (FR), dosage of pesticide per sown area (DP), agricultural machinery power per sown area (AM), irrigation proportion of arable land (IP) and irrigation efficiency (IE).

\section{Discussion}

The development of irrigation can increase the crop yields and ensure food security, and the country's food production may increase to 170 million tons ${ }^{[3]}$. However, this technology also faces the problem of water use efficiency. The MWP reflects the true performance of the irrigation water inputs and the extent of the irrigation development, determine whether a region is suitable for continued irrigation. And apparently, such consideration should also include the local water resources, farmland sustainability and any environmental sustainability requirements as well.

Irrigation can increase the food production across the country. And some regions in China had large MWP, indicating that small farmland irrigation rate is capable to have significantly impact (in the second quadrant of Figure 4). With the consideration of water resources exploitation degree and food production situation, this treatment should be encouraged. The northwest PAMs including Ningxia, Gansu, Shanxi, Shaanxi and Qinghai provinces belong to high water pressure area (Figure 4), the WSI (the water withdrawal criticality ratio arising from water withdrawal from water availability) is more than 0.4 although the irrigation rate of these regions has increased potential. In these regions, limited water resource restricts the further expansion of the irrigated area, provides only a small grain production and a limited contribution to the country. In addition, water resources are the key elements to maintain the ecological development of these arid and ecologically fragile areas. Therefore, expansion of the irrigation area should be limited to restrict the occupation of water resources. Although the MWP is smaller in the southwestern provinces (except Sichuan), these provinces are rich in water resources and belong to low or no water resource stress areas. At the same time, the grain production capacity in these provinces has a contribution rate of more than $2.00 \%$, and the farmland irrigation rate is lower than the national level. Thus, these areas should further expand the irrigated area to increase the grain output, make a more important contribution to national food security. The main grain producing areas in the northeast (Heilongiiang, Jilin, Liaoning and Inner Mongolia) is China's most important granary, these four provinces provides $1 / 4$ of the country's grain production. However, these four provinces are in the third quadrant, and WSI are all more than
0.4 , which means they are facing the problem of severe water resources limitation and the irrigation water resources output capacity is small and wasteful. Therefore, the northeastern provinces should focus on the development and promotion of efficient water-saving irrigation technology to reduce the input of the irrigation water resources and alleviate the pressure of the water resources, ensuring the smooth progress of grain production and the stability of national food security.

In Figure 4, the intersection point of the coordinates axes is the national value of the MWP and IP; the number of brackets after the province name is the proportion of grain contribution in this region; the water resources pressure index is the ratio of water consumption to total available water resources.

The main grain producing areas of the North China Plain, including Henan, Shandong and Hebei, contributed $22.71 \%$ of China's grain production. This area has similar food and virtual water output as the Northeast $\mathrm{China}^{[8]}$, but faces high water pressure. The MWP in these regions is almost the highest in the country, and the space for saving irrigation is relatively limited. In this area, it is possible to achieve a sustainable supply of water resources without reducing the food production by changing the irrigation patterns while considering inter-basin diversion. As the food production is mostly negligible, Beijing, Shanghai and Tianjin may consider reducing their investment in agricultural water use, allocating the limited water resources for domestic and industrial requirement. The MWP of the major grain-producing areas (Jiangxi, Hunan, Hubei, Anhui and Jiangsu) in the Yangtze River Basin is close to the national level. In these regions, water resources are abundant and the generally high proportion of irrigation limits the space for further expansion, thus irrigated area can be increased to further improving the MWP. Applying water resources to socio-economic development will achieve comprehensive social progress. Other areas in the southeastern provinces are more developed and abundant in water resources. At the same time, the MWP of these provinces is low. These areas belong to the food and virtual water input areas in China. They should actively improve their irrigation water production capacity and total grain output, reduce their external dependence to ease the water pressure in the northern grain output area. 


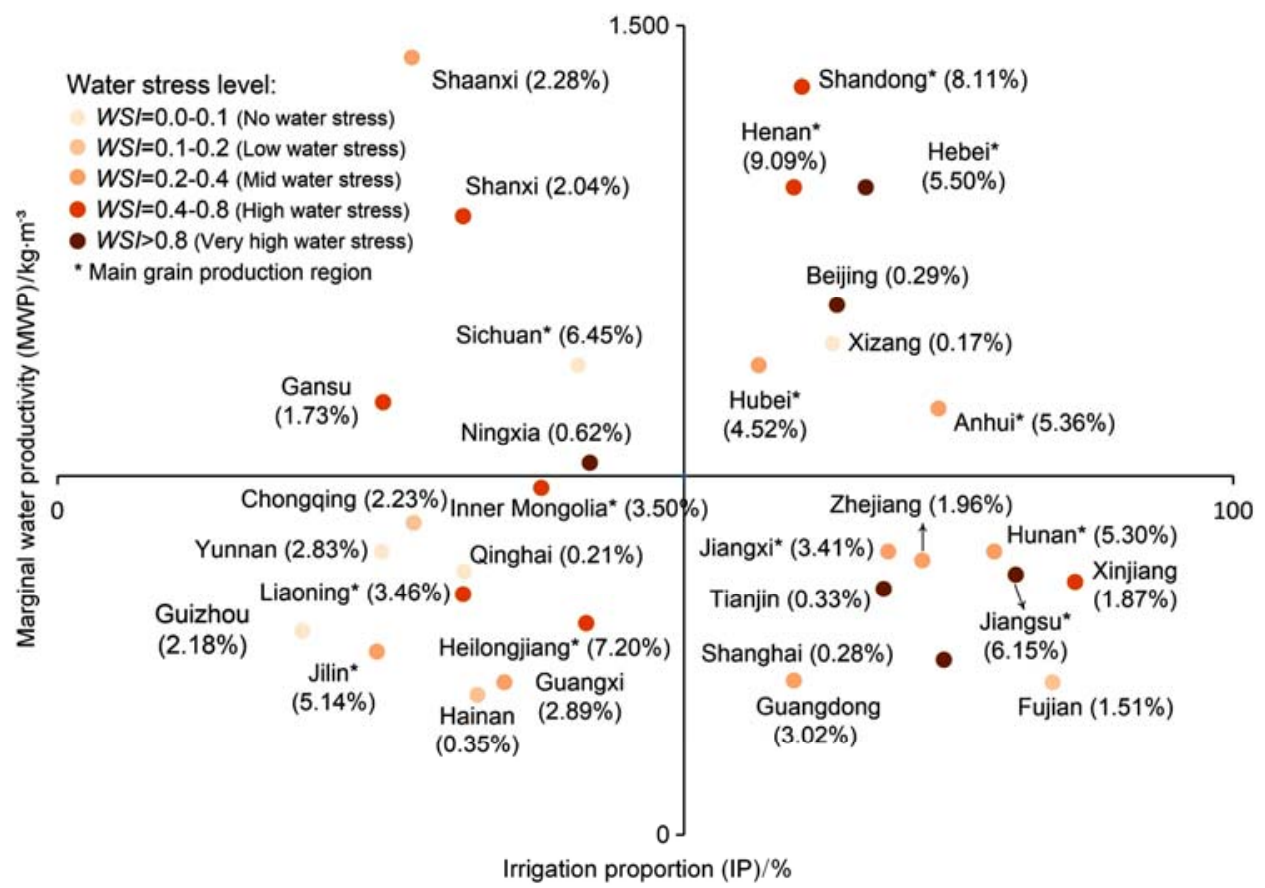

Figure 4 Distribution of the marginal water productivity and irrigation proportion of arable land (IP) in China

\section{Conclusions}

In order to split up the role of precipitation in the crop yield formation, the MWP was presented in this study. It can accurately reflect the performance and production capacity of the irrigation water resources in an agricultural production system. Therefore, the most direct way to improve the efficiency of irrigation water use in a region is to improve the MWP. The growth of MWP in China, approximately $3.4 \%$ per year, is the reason of continuously increased food production during 1998-2010 based on stable agricultural water application. However, the current MWP of China is only $0.665 \mathrm{~kg} / \mathrm{m}^{3}$, allows a considerable room for improvement. The Moran's I of MWP was around 0.400 and it has a spatial distribution pattern that does not change over time. The temperature and precipitation are the primary factors that affect the MWP, which are the primary reasons for the significant aggregation of the MWP in space. In addition, the impact of the fertilizer and agricultural machinery power per sown area on the MWP cannot be ignored, and the MWP can also be further promoted by improving agricultural production conditions. Given the pattern of the temporal and spatial distribution of MWP, each region should develop specific strategies to improve the irrigation water use efficiency on their own water resource endowments and the extent of irrigation development, ensure the national food security and develop the sustainable use of water resources. Improving irrigation efficiency and reducing irrigation water per unit area is a direct measure to improve MWP. In addition, ameliorating crop varieties and raising crop yield can also contribute significantly to the promotion of regional MWP.

\section{Acknowledgments}

This work is jointly funded by the National Key R\&D Program of China (2017YFD0201507), the National Natural Science Foundation of China (51609065), the social science fund of Jiangsu Province (17GLC013), the China Postdoctoral Science Foundation funded project (Grant No. 2018T110436, 2017M611681) and the
Water Conservancy Science and Technology Project of Jiangsu Province.

\section{[References]}

[1] Cao X C, Wu M Y, Zheng Y L, Guo X P, Chen D, Wang W G. Can China achieve food security through the development of irrigation? Regional Environmental Change, 2018; 18(2): 465-475.

[2] Zhu X, Li Y, Li M, Pan Y, Shi P. Agricultural irrigation in China. Journal of Soil and Water Conservation, 2013; 68(6): 147A-154A.

[3] Cao X, Wang Y, Wu P, Zhao X, Wang J. An evaluation of the water utilization and grain production of irrigated and rain-fed croplands in China. Science of the Total Environment, 2015; 529: 10-20.

[4] Murray A, Ray I. Wastewater for agriculture: A reuse-oriented planning model and its application in peri-urban China. Water Research, 2010; 44(5): 1667-1679

[5] Wu P T, Jin J M, Zhao X N. Impact of climate change and irrigation technology advancement on agricultural water use in China. Climatic Change, 2010; 100: 797-805.

[6] Gong P, Yin Y Y, Yu C Q. China: Invest wisely in sustainable water use. Science, 2011; 331(6022): 1264-1265.

[7] Cao X C, Wu M Y, Guo X P, Zheng Y L, Gong Y, Wu N, Wang W G. Assessing water scarcity in agricultural production system based on the generalized water resources and water footprint framework. Science of the Total Environment, 2017; 609: 587-597.

[8] Wang Y B, Wu P T, Zhao X N, Engel B A. Virtual water flows of grain within China and its impact on water resource and grain security in 2010. Ecological Engineering, 2014; 69: 255-264.

[9] Playan E, Mateos L. Modernization and optimization of irrigation systems to increase water productivity. Agric Water Manage, 2006; 80: $100-116$.

[10] Rodrigues G C, Pereira L S. Assessing economic impacts of deficit irrigation as related to water productivity and water costs. Biosystems Engineering, 2009; 103: 536-551.

[11] Cao X, Ren J, Wu M, Guo X, Wang Z, Wang W. Effective use rate of generalized water resources assessment and to improve agricultural water use efficiency evaluation index system. Ecological Indicators, 2018; 86: 58-66.

[12] Maynard C M. Accessing the environment: Delivering ecological and societal benefits through knowledge integration-The case of water management. Applied Geography, 2015; 58: 94-104.

[13] Bitterman P, Tate E, Van Meter K J, Basu N B. Water security and rainwater harvesting: A conceptual framework and candidate indicators. Applied Geography, 2016; 76: 75-84. 
[14] Jensen M. Beyond irrigation efficiency. Irrigation Science, 2007; 25: 233-245.

[15] Bruce L. Fictions, fractions, factorials and fractures; on the framing of irrigation efficiency. Agricultural Water Management, 2012; 108: 27-38.

[16] Cao X, Wu M, Shu R, Zhuo L, Chen D, Shao G, et al. Water footprint assessment for crop production based on field measurements: A case study of irrigated paddy rice in East China. Science of the Total Environment, 2018; 610-611: 84-93.

[17] Qureshi M E, Grafton R Q, Kirby M, Hanjra M A. Understanding irrigation water use efficiency at different scales for better policy reform: a case study of the Murray-Darling Basin, Australia. Water Policy, 2011; 13(1): 1-17.

[18] Azad M, Ancev T, Hernandez-Sancho F. Efficient Water Use for Sustainable Irrigation Industry. Water Resources Management, 2015; 29(5): 1683-1696.

[19] Molden D J. Accounting for water use and productivity. SWIM Paper 1, International Irrigation Management Institute, Colombo, Sri Lanka, 1997.

[20] Xiao G J, Zheng F J, Qiu Z J, Yao Y B. Impact of climate change on water use efficiency by wheat, potato and corn in semiarid areas of China. Agriculture, Ecosystems \& Environment, 2013; 181: 108-114.

[21] Ali M K, Klein K K. Water use efficiency and productivity of the irrigation districts in southern Alberta. Water Resources Management, 2014; 28: 2751-2766

[22] Pereira LS, Cordery I, Iacovides I. Improved indicators of water use performance and productivity for sustainable water conservation and saving. Agricultural Water Management, 2012; 108: 39-51.

[23] Cao X, Wang Y, Wu P, Zhao X. Water productivity evaluation for grain crops in irrigated regions of China. Ecological indicators, 2015; 55: $107-117$.

[24] Jagermeyr J, Gerten D, Heinke J, Schaphoff S, Kummu M, Lucht W. Water savings potentials of irrigation systems: global simulation of processes and linkages. Hydrology and Earth System Sciences, 2015; 19(7): 3073-3091.

[25] Jabro J D, Stevens W B, Iverson W M, Evans R G, Allen B L. Crop waterproductivity of sugarbeet as affected by tillage. Agronomy Journal, 2014; 106(6): 2280-2286

[26] Cao X C, Shu R, Chen D, Guo X P, Wang W G. Temporal-spatial distributions of water use and productivity of maize in China. The Journal of Agricultural Science, 2018; 156(4): 1-9.

[27] Roth G, Harris G, Gillies M, Montgomery J, Wigginton D. Water-use efficiency and productivity trends in Australian irrigated cotton: A review.
Crop \& Pasture Science, 2013; 64(11-12): 1033-1048.

[28] Gao Z. Development and action of irrigation in China. Journal of Economics of Water Resources, 2006; 24(1): 36-39. (in Chinese)

[29] Liu J, Wiberg D, Zehnder A J B, Yang H. Modelling the role of irrigation in winter wheat yield and crop water productivity in China. Irrigation Science, 2007; 26(1): 21-33.

[30] Cao X, Wu P, Wang Y, Zhao X. Assessing blue and green water utilisation in wheat production of China from the perspectives of water footprint and total water use. Hydrology and Earth System Sciences, 2014; 18(8): 3165-3178.

[31] Sieber S, Pannell D, Müller K, Holm-Müller K, Kreins P, Gutsche V. Modelling pesticide risk: a marginal cost-benefit analysis of an environmental buffer-zone programme. Land Use Policy, 2010; 27: 653-661.

[32] Franczyk J, Chang H. Spatial analysis of water use in Oregon, USA, 1985-2005. Water Resour. Manage, 2009; 23: 755-774.

[33] Hoyos N, Escobar J, Restrepo J, Arango A, Ortiz J. Impact of the 2010-2011 La Niña phenomenon in Colombia, South America: the human toll of an extreme weather event. Applied Geography, 2013; 39: 16-25.

[34] Wang Y, Wang S, Li G, Zhang H, Jin L, Su Y, Wu K. Identifying the determinants of housing prices in China using spatial regression and the geographical detector technique. Applied Geography, 2017; 79: 26-36.

[35] Mark R T, Philip D, Marie-Josée F, Pierre L, Donald E M, Michael S R. Conceptual and mathematical relationships among methods for spatial analysis. Ecography, 2002; 25: 558-577.

[36] Moran PAP. Notes on continuous stochastic phenomena. Biometrika, 1950; 37: 17-23.

[37] Lee S. A generalized significance testing method for global measures of spatial association: an extension of the Mantel test. Environ. Plann. A, 2004; 36: 1687-1703.

[38] Ma Z, Zuckerberg B, Porter W F, Zhang L. Use of localized descriptive statistics for exploring the spatial pattern changes of bird species richness at multiple scales. Applied Geography, 2012; 32(2): 185-194.

[39] Anselin L. GeoDa0.95i Release Notes. Spatial analysis laboratory (SAL). Department of agricultural and consumer economics, University of Illinois, Urbana-Champaign, IL, 2004.

[40] Luo Q Y, Bange M, Johnston D, Braunack M. Cotton crop water use and water use efficiency in a changing climate. Agriculture, Ecosystems \& Environment, 2015; 202: 126-134.

[41] Shao G, Huang D, Cheng X, Cui J, Zhang Z. Path analysis of sap flow of tomato under rain shelters in response to drought stress. International Journal of Agricultural \& Biological Engineering, 2016; 9(2): 54-62. 